$\Phi=\Phi$

\title{
A process for the development of a psychosocial educational programme to facilitate the reintegration of incarcerated women who had dumped babies and / or committed infanticide in Namibia
}

\author{
Sumpi Ndempavali *, Amukugo Hans Justus \\ Lecturers, School of nursing and School of Public health, Faculty of health Sciences University of Namibia \\ *Corresponding author E-mail: nsumpi@unam.na
}

\begin{abstract}
The aim of this paper is to describe the steps/process used to develop a psychosocial educational programme to facilitate the reintegration of incarcerated women who had dumped babies and / or committed infanticide in Namibia. This process was done in four phases namely Phase 1, was carried out to explore and describe the lived experiences of women who had dumped and / or committed infanticide. The researcher used in-depth unstructured individual interviews for data collection and data was analysed by using Tech's method of qualitative data analysis. Phase 2, focuses on the conceptualisation framework guided the development of a psychosocial educational programme that facilitated the reintegration process of women who had dumped and / or committed infanticide. The educational programme included the activities suggested in the survey list of Dickoff et al. (1968); namely, agent, recipient, context, dynamics, procedures, and terminus. Phase 3, focused on the development of a psychosocial educational programme to facilitate the reintegration process of women who had dumped their babies and / or committed infanticide. The survey list of Dickoff et al. (1968) was adopted as a reasoning map in the construction of the development of a psychosocial educational programme, as well as the findings of the situational analysis of this study. And Phase 4, focused on the implementation and evaluation of the psychosocial educational programme that was developed to facilitate the reintegration of incarcerated women who had dumped babies and / or committed infanticide. A three-day training workshop was held at the Oluno Correctional Facility to conduct the educational programme. The educational programme was evaluated in order to validate whether the programme interventions were likely to bring about the desired change among the participants.
\end{abstract}

Keywords: Process, Psychosocial; Educational Programme; Facilitate; Reintegration; Incarcerated, Women; Dumped Babies Committed; Infanticide.

\section{Introduction}

In Namibia, baby dumping and infanticide is a criminal act punishable by law. This implies that when a mother is prosecuted she may be sentence to prison with charges of murder and concealment of birth. Owing to this fear of being prosecuted for baby dumping and infanticide that is often associated with concealment of birth, Namibia lacks accurate figures on the incidence of baby dumping and infanticide because such instances are either underreported or not recorded separately from other murders (Ministry of Gender Equality and Child Welfare, 2009).

The Baby Dumping Prevention Awareness Campaign (2014) reports that over the years, Namibia have seen numerous reports of baby dumping that is on the increase. The first case of baby dumping and infanticide was reported in either 1938 or 1939 during the colonial period (Hubbard, 2008). However, these incidences have increased gradually since then, for example from six cases in 2003 to 23 cases in 2007 (Ministry of Gender Equality and Child Welfare (MGECW), 2009). Lewis Kim (2013) also reports that about 40 babies and foetuses are dumped or flushed down toilets every month in Windhoek, the capital city of Namibia. In the same vein, the 2010 United Nations Children's Fund Report on children and adolescents in Namibia reveals that thirteen dead babies are found every month at the sewage works in Windhoek. According to the
Baby Dumping Prevention Awareness Campaign (2014), Namibia is forced to recognized baby dumping and infanticide not only as a criminal act, but also as a social and public health problem that has an impact on the child mortality rate in Namibia, which currently stands at 45.64 deaths per 1000 live births. That places Namibia in the 47th position of the 2014 World Infant Mortality Baby dumping and infanticide have become social phenomena with grave consequences that are drawing nationwide attention and condemnation in Namibia. Those women who are perpetrating these heinous acts provide numerous motives; such as fathers denying paternity, unemployment, young mothers who still want to continue with school, as well as a lack of awareness about institutional care, foster homes, and formal adoption. These young incarcerated women before and after having dumped their babies and / or committed infanticide, are psychologically and emotionally traumatized. That left them fearful to be reintegrated into the society upon releases, hence the need for a psychosocial educational programme to facilitate their reintegration.

In this study, the researcher explored and described the views of women who had dumped babies and / or committed infanticide with regard to their experiences with the purpose of developing, implementing, and evaluating an educational programme to facilitate their reintegration upon release with their families and with society in general in the Oshana Region, Namibia. The study was 
qualitative, explorative, descriptive, and contextual in nature and was conducted in four phases, namely:

Phase 1: This phase comprised a situational analysis. It was carried out to explore and describe the lived experiences of women who had dumped and / or committed infanticide. The researcher used in-depth unstructured individual interviews for data collection and focus group discussions. Data was analysed by using Tech's method of qualitative data analysis. The findings of this study identified psychological challenges, fear for reintegration, socio-economic challenges, as well as legal and ethical challenges that were encountered by women who had dumped babies and / or committed infanticide. These findings led to the development of the psychosocial educational programme to address those challenges.

Phase 2: During this phase, the conceptualisation framework guided the development of a psychosocial educational programme that facilitated the reintegration process of women who had dumped and / or committed infanticide. Dickoff, James and Wiedenbach (1968) identify the following three essential ingredients of a conceptual framework; namely, goal content, which is specified as the aim of the activity, prescription of the activity for goal realisation, and a survey list that accompanies the presentation of the prescription for the activity in terms of the goal realisation. The educational programme included the activities suggested in the survey list of Dickoff et al. (1968); namely, agent, recipient, context, dynamics, procedures, and terminus.

Phase 3: This phase focused on the development of a psychosocial educational programme to facilitate the reintegration process of women who had dumped their babies and / or committed infanticide. The survey list of Dickoff et al. (1968) was adopted as a reasoning map in the construction of the development of a psychosocial educational programme, as well as the findings of the situational analysis of this study.

Phase 4: This phase focused on the implementation and evaluation of the psychosocial educational programme that was developed to facilitate the reintegration of incarcerated women who had dumped babies and / or committed infanticide. A three-day training workshop was held at the Oluno Correctional Facility to conduct the educational programme. The educational programme was evaluated in order to validate whether the programme interventions were likely to bring about the desired change among the participants.

The evaluation of the programme was conducted immediately after every session and at the end of the training programme. The programme outcomes evaluation was carried out three months after the educational programme had been implemented. The programme participants commented that the programme implementation was useful, as well as informative and educative.

\section{Purpose}

The aim of the study was to develop, describe, implement, and evaluate a psycho-social training programme to facilitate the reintegration of the imprisoned women who had dumped and / or committed infanticide in the Oshana Region of Namibia.

\section{Objective}

The following objectives support the aim of study were to :

- Explore and describe the experiences of women who had dumped their babies and / or committed infanticide in the Oshana Region.

- Describe a conceptual framework that facilitates the development of the psychosocial training programme for women who had committed infanticide and / or dumped their babies in the Oshana Region.

- Develop and describe a psychosocial training programme for women who had dumped babies and / or committed infanticide in the Oshana Region.
- Implement and evaluate a psychosocial training programme for women who had dumped babies and / or committed infanticide in the Oshana Region.

\section{Methodology}

The research method can be defined as a systematic set of techniques and procedures followed by a researcher when collecting and analysing data. It refers to the individual steps advanced procedures and strategies used by the researcher when collecting and analysing data during the research process (Babbie \& Mouton 2009). Effective research methods ensure that a research question is answered as reliably as possible, so that the objectives of the study may be achieved (Creswell, Rocco \& Hachert 2011). For this study, individual in-depth interviews were applied. The researcher kept written records of all the observations made and noticed with each interview and a tape recorder was used to capture all information regarding the interview. This study was carried out in four phases, namely situation analysis, development of the conceptual framework, programme development, programme implementation \& evaluation.

The sampling criteria were met when the study subjects only included women who had dumped babies and / or committed infanticide; those with the first-hand experience of dumping their babies. The subjects were able to express their experiences in a language they were comfortable with and which the researcher understood. The sampling criteria facilitated the sampling process. The researcher used a non-probability purposive sampling technique to select the study subjects. Homogeneous sampling, which was one strategy of purposive sampling was used in this study because it relied on the judgment of the researcher to select participants who were similar based on the knowledge about the research phenomenon of interest and the assistance they could give to achieve the research purpose and objectives (Babbie \& Mouton, 2009). The researcher also used a non-probability purposive sampling technique to select the community members and the correctional officers as part of the sample.

A situational analysis had been introduced as a planning step that assisted the researcher to gain an in-depth understanding of the experiences of women who had dumped their babies and / or committed infanticide in their respective social environments.

The accessible population was women who had dumped their babies to whom the researcher has reasonable access. The target population was women who had dumped babies and / or committed infanticide who met the sampling criteria. The sampling criteria were met when the study subjects only included women who had dumped babies and / or committed infanticide; those with the first-hand experience of dumping their babies. The subjects were able to express their experiences in a language they were comfortable with and which the researcher understood. The sampling criteria facilitated the sampling process. The researcher used a non-probability purposive sampling technique to select the study subjects. Homogeneous sampling, which was one strategy of purposive sampling, was used in this study because it relied on the judgment of the researcher to select participants who were similar based on the knowledge about the research phenomenon of interest and the assistance they could give to achieve the research purpose and objectives (Babbie \& Mouton, 2009). The researcher also used a non-probability purposive sampling technique to select the community members and the correctional officers as part of the sample.In this study, the sampling inclusion criteria upon which the selection of the participants was based were:

- Women who had been found guilty of either dumping a baby and / or committed infanticide and who were incarcerated at the Oluno Correctional Facility in Oshana region of the Ondangwa constituency in Namibia,

- Women who freely and voluntarily gave informed consent to be interviewed. 
- Women who were able to speak and understand either Oshiwambo or English or both; the languages that that the researcher was conversant in.

All 11 women who had dumped their babies and / or committed infanticide in they were in jail that time the study conducted were interviewed. The unstructured individual interviews were beneficial because the participants became comfortable enough to describe experiences highly sensitive and critical in nature without fear that someone else would overhear the opinions they were expressing. Participants were also comfortable enough to supply meticulous descriptions that enabled the researcher to understand the phenomenon without fear of wasting time unnecessarily during the interview sessions. The participants were comfortable, since the unstructured interviews took place in a setting that was familiar to them (Watson, 2011).

The researcher aimed at gathering rich and in-depth description of the lived experiences of the research participants from their point of view. The grand / central question was put to each participant in the same manner: "Tell me about your experience of baby dumping and / or committing infanticide?"

Focus group discussion was held for women who dumped babies and / or committed infanticide, community members and correctional officers respectively. The central question was posed to these groups in the same manner: "Tell me about your experience of baby dumping and infanticide and tell me how you would like this problem to be addressed?"

Qualitative data analysis requires insight, creativity, initiative, conceptuality, as well as sensitivity and is more complex than the statistical analysis of quantitative data (Groenewald, 2004). Furthermore, Groenewald (2004) emphasises that qualitative analysis processes focus on searching for meanings and relationships among categories and generating themes. Thus, the data is dissembled, conceptualized and put back together in a different way. The purpose of this study was to develop a psychosocial training programme, and the explorative research design and method adopted justified the use of a qualitative content analysis. Data analysis in qualitative research is an active and interactive process. Therefore, the researcher immersed herself in the data to search for meaning and to develop an understanding of women who had dumped their babies (Polit \& Beck, 2012).

In this study, data collection and data analysis occurred concurrently. The researcher used qualitative analysis techniques to analyse words rather than numbers. The researcher utilised Tesch's descriptive method of data analysis (De Vos, 2009; Creswell 2008 Roberts, 2004) by using an open coding method to analyse, organise, and interpret data:

The voice recordings were carefully transcribed verbatim and those transcripts from the data collection process in conjunction with the field notes were used while the researcher was also listening to the recorded interviews with the purpose of obtaining a sense of the bigger picture.

In view of the fact that all the participants spoke in their vernacular (Oshiwambo) language except for two who spoke in English the translation from the vernacular language to English was a necessity. The researcher read the individual transcripts again while writing notes in the margin. The researcher dissembled the data and examined it closely. Similar ideas and meanings were clustered together and then grouped into unique themes. the most descriptive wording was found and turned into themes. The themes were reduced by arranging topics that related to one another and lines were drawn to show the interrelationships between themes. Three (3) themes and eleven (11) sub-themes were identified.

The researcher developed the conceptual framework after the data had been collected and analysed. A conceptual framework is potentially useful as a tool to scaffold research and, therefore, to assist a researcher to make meaning of subsequent findings (Reichel \& Ramey, 2009). The framework formed the basis for the educational programme with the purpose of reintegrating women successfully who had dumped babies and / or committed infanticide. The conceptual framework for an educational programme in this study was constructed according to the three essential ingredients of a situation-producing conceptual framework as proposed by Dickoff, James, and Wiedenbach (1968); i.e. goal-content, activities prescription, and a survey list.

The researcher used the ideas of Dickoff et al. (1968) to formulate the conceptual framework used in this study. The survey list of Dickoff et al. (1968) includes the context, agent, recipient, dynamics, procedure of the activity, and terminus. Who is the agent? Who is the recipient? What is the procedure? What are the dynamics? What is the context? What is the outcome? These concepts were used as the basis for the formulation of the conceptual framework.

Dickoff et al. (1968) further mention three issues that need to be addressed in the development of the conceptual framework; namely the goal content, the prescriptions of the activity to attain the desired outcome, and the survey list to identify the gap between the intended activity and the prescriptions for the activity. The aim of the framework was to identify major concepts that could be reflected in the educational programme aimed at assisting women who had dumped babies and / or committed infanticide. Those concepts were utilised to develop the theoretical framework of the guidelines for women who had dumped babies and / or committed infanticide. The researcher's mind map symbolized the interaction between the agent and the recipients to inform the contextualization within a specific framework and procedure. The context determined the procedure to be followed, whilst acknowledging the dynamics that were reinforcing both the interaction and the facilitation of reintegration process with the aim of accomplishing specific goals or outcomes.

This phase entailed the development and implementation of the educational programme. The educational programme was developed according to the themes that had been extracted from the interviews and from the field notes. The implementation was designed to cover topics that assisted women who had dumped babies and / or committed infanticide during their reintegration period. The implementation was in the format of a workshop, conducted over three days to include the orientation, working, and terminal phases.

It was vital to evaluate the guidelines after they had been implemented to enable the researcher to identify the weaknesses of the guidelines with the purpose of affecting the necessary improvements. Written and / or verbal feedback events were conducted after the daily workshops with the participants through evaluation forms. A follow-up was conducted after two months with all the women who had dumped babies and / or committed infanticide and attended the workshop to evaluate the effectiveness of the guidelines (Chapter 6). Figure 2.1 illustrates the four phases of this research study. 

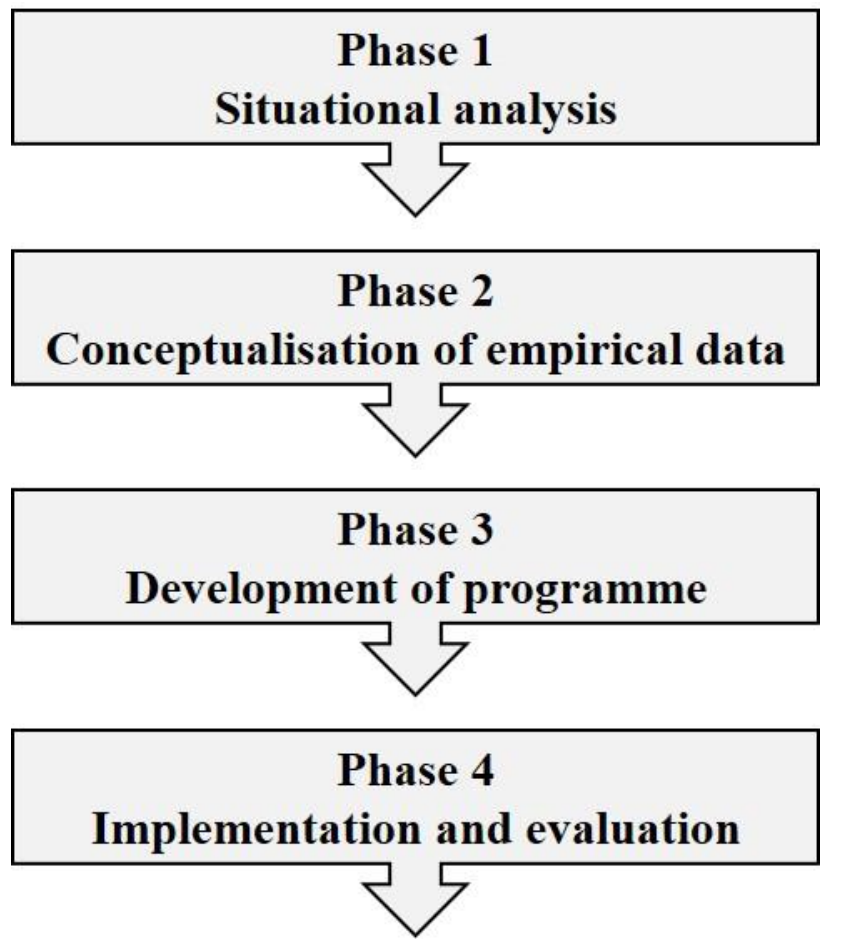

Fig. 1: Illustration of the Four Phases of the Research Study.

Reasoning: In view of the fact that qualitative studies use a phenomenological perspective, reasoning designs are discussed in accordance with their application to this research. The researcher used the following reasoning design principles to generate knowledge about women who had dumped their babies and / or committed infanticide and to develop guidelines: inductive reasoning, deductive reasoning, infer, bracketing, and reflection.

The reasoning during deduction is incomplete and it is possible to develop conclusions before a researcher confirms these conclusions with the research participants. Therefore, it becomes more important that researchers have to prove all their claims (De Vos et al., 2006). Deductive reasoning is used in research to confirm whether a researcher's assumptions are true or not for the purpose of the study (Babbie \& Mouton, 2009). Deductive reasoning was used as the survey list: agent, recipient, context, dynamics, procedure, and terminus. In Chapter 6, deductive analysis was applied to describe the guidelines for operationalising the programme for women who had dumped babies and / or committed infanticide. The researcher used deductive reasoning in this study to conduct the literature control and to formulate practical guidelines for operationalization.

An inference is a meaning that is suggested rather than directly stated. Inferences are implied through clues that lead the reader to make assumptions and draw conclusions. Mouton (2006) explains that drawing an inference refers to a logic declaration that one makes from a premise to a conclusion.

During conceptualisation and the development of the training programme, inferential reasoning was used in the literature review investigation to clarify the meaning of women who had dumped infanticide their babies and / or committed infanticide.

Bracketing is used in research when a researcher suspends what is known about the research phenomenon, to allow the data to convey undistorted information as described by the participants themselves (Brink, 2006; De Vos et al., 2001). In this study, the researcher had to identify and write down her own principles, assumptions, biases, descriptions of her own perceptions, and what was known about the topic before beginning with the interview sessions with the purpose of bracketing these factors during the interview sessions. Through bracketing (reductionism), a researcher holds in abeyance ideas, preconceptions, and personal knowledge (Groenewald, 2004). The goal of a researcher is to achieve transcendental subjectivity, which in turn, denotes that the impact of the researcher on the inquiry is constantly assessed by neutralizing biases and preconceptions. The aim is to allow a researcher to view the phenomenon in its uncontaminated nature. This recommendation concurs with Husserl's (in Bernard \& Ryan 2010) conviction that it is not only necessary to bracket an individual's consciousness, but also that of the outer world; as acquired through society, culture and history; and which may be contained in the literature reviewed. In this study, the researcher took these arguments into account by deciding that each description of the experience of women who had dumped babies and / or committed infanticide contained certain unique experiences. In addition, each of those experiences included features that were intrinsic to that experience and which made the experience what it was. Therefore, it might not be possible to generalise the findings to other experiences of the same phenomenon. This background was present throughout the interpretive process and, although it informed the interpretations of the data, it did not influence them. This technique enabled the researcher to constrain personal biases by "bracketing out" the self and examining her own prejudgement in order to obtain a clear picture of the people investigated (Burns \& Grove, 2009; Polit \& Beck, 2008). Furthermore, bracketing is a process that puts aside the knowledge and opinions with regard to the phenomenon being investigated and already known to the researcher to prevent them influencing the data.

Reflexivity is a process of reflecting critically on self and of analysing and making note of personal values that could affect data collection and interpretation (Polit \& Beck, 2008). Researcher credibility refers to the faith that can be put in the researcher to enhance the research (Polit \& Beck, 2008).

Reflexivity was continually used during this study because the researcher guarded against the potential influence that might have contaminated the research design, the setting, her behaviour during data collection, data discussion, interpretation, and presentation (Hennink, Hutter \& Bailey, 2011). Reflexivity between the researcher and the participants was achieved during the interviews through acknowledging and reacting to their backgrounds, characteristics, and positioning. During the interviews, the researcher and the participant contributed to the co-construction of reality about the research phenomenon (Hennink et al., 2011).

- Ethical aspect and principles

Conducting research is guided by ethics which are guiding the researcher in order to be able to provide a safe environment and protection to the participant of the study. Furthermore, ethics is associated with the mechanism for researcher accountability and responsibility. In research, ethical measures need to be put in place in order to ensure that the rights of the participants are not violated. Ethical measures are important at all stages of the research process and must be in place from the start of the research to the end (Brink, 2007).

It is the researcher's responsibility to conduct nursing research in an ethical manner. To conduct research in an ethical manner means that the researcher must carry out the research competently, manage resources honestly, and acknowledge fairly those who contributed guidance or assistance. Communicating results accurately and considering the consequences of the research for society are also part of ethical research. Failure to meet this responsibility undermines the whole scientific process and may lead to many unfortunate and problematic consequences (Brink, 2007). The ethical considerations that were used for this study are described below (Brink, 2007; Kobus, 2007).

- Measures to ensure trust

The researcher adopted strategies suggested by Lincoln and Guba as cited by Tappen (2011) to establish trustworthiness of the data. These strategies describe trustworthiness as "the degree of confidence that the qualitative researcher have in their data by using the criteria of credibility (trust-value), transferability (applicability), dependability (consistency), and confirmability (neutrality)". The researcher applied these criteria of Guba's model (Guba \& Lincoln, 2005) to enhance the trustworthiness of this study.

Credibility: In this study, credibility was maintained through prolonged engagement, persistent observation, triangulation, referential adequacy, peer group debriefing, and member checking. Bow- 
en (2005) refers to the confidence one has in the truth of the findings of a study that could be established by complying with different methods, e.g. prolonged engagement and support. In this study, credibility was ensured by prolonged engagement during the unstructured individual interviews. Participants were allowed to describe their experiences with regard to the research topic for a month and a half until data saturation occurred. Each interview took about 45 minutes which allowed for thorough exploration of the experiences of women who had dumped babies and / or committed infanticide. Triangulation was ensured by conducting both focus group discussions and unstructured individual interviews sessions. The agreement on themes and sub-themes was reached by having a consensus meeting with an external coder. Focus group interview sessions and all unstructured individual interviews were captured by using a voice recorder (Babbie \& Mouton, 2009). These interviews enabled the researcher to understand the lived experiences of women who had dumped babies and / or committed infanticide. A debriefing session with an experienced qualitative researcher and the researcher was held after the interviews had been conducted. The purpose of the debriefing session was to learn from the feedback by the experienced qualitative researcher and to clarify issues that had occurred during the interviews (Onwuegbuzie, Leech \& Collins, 2008).

These issues included confirming and assessing the intentions of the participants, correcting obvious errors, and allowing additional information to be supplied voluntarily by participants (Babbie \& Mouton, 2009).

Verification of this programme was done by involving the participants who verified whether the study results represented what they have described during the interview sessions, and indicated whether the developed programme would address their needs during the workshop. Table 2.1 summarises the strategy for ensuring trustworthiness of credibility.

Table 1: Criteria for and Application of Credibility

\begin{tabular}{|c|c|c|}
\hline Strategy & Criteria & Application \\
\hline \multirow{7}{*}{ Credibility } & $\begin{array}{l}\text { Prolonged field } \\
\text { perception }\end{array}$ & $\begin{array}{l}\text { - } \quad \text { Researcher collected data from August and half of September in } 2012 \text {. } \\
\text { The researcher went to the field in July } 2015 \text { and conducted a workshop to verify whether the study } \\
\text { results represented experiences that the participants shared during the interviews and whether the } \\
\text { developed programme would address their needs during the reintegration process. }\end{array}$ \\
\hline & $\begin{array}{l}\text { Examine the phe- } \\
\text { nomenon under } \\
\text { different circum- } \\
\text { stances }\end{array}$ & $\begin{array}{l}\text { - The researcher was involved in data collection at the Oluno Correctional Facility. } \\
\text { The researcher persistently observed the participants all the time during focus group discussions } \\
\text { and individual interviews. } \\
\text { - While conducting the educational programme, the researcher also observed the participants. }\end{array}$ \\
\hline & $\begin{array}{l}\text { Flexibility (field } \\
\text { journal) }\end{array}$ & $\begin{array}{l}\text { - Researcher participated fully in the research during the research proposal development, data collec- } \\
\text { tion, data analysis, and data interpretation. }\end{array}$ \\
\hline & Triangulation & $\begin{array}{l}\text { Elven unstructured individual interviews and one focus group interview were used during the data } \\
\text { collection process. } \\
\text { A voice recorder was used to capture all interviews. } \\
\text { - Field notes were taken during all the interviews. } \\
\text { - Bracketing was done as well. }\end{array}$ \\
\hline & Interview techniques & $\begin{array}{l}\text { - Reflecting, timing, paraphrasing, clarifying, focusing, silence, and probing were used during the } \\
\text { interview. } \\
\text { - Interpersonal attitudes; such as congruency, acceptance, and empathy were also employed. } \\
\text { - Focus group discussion and unstructured individual interviews were used. }\end{array}$ \\
\hline & $\begin{array}{l}\text { Structural coher- } \\
\text { ences }\end{array}$ & - $\quad$ Data analysis process: The Tesch's (1992) eight steps for data analysis were used. \\
\hline & $\begin{array}{l}\text { Referential adequa- } \\
\text { cy }\end{array}$ & $\begin{array}{l}\text { - The researcher underwent specific training before the commencement of the research process - } \\
\text { doctoral programme at the University of Namibia. }\end{array}$ \\
\hline
\end{tabular}

Transferability: Transferability was ensured through thick, descriptive, clear criteria for nominating the sample and time sampling, as well as a clear description of the participants based on the intensive way in which the data was collected. Transferability means that other researchers could apply the findings to their own settings, using the research methods that another researcher has used, provided it was described thoroughly (Bowen, 2005). Furthermore, transferability refers to the extent in which the findings of the study could be transferred to another context or with other participants. In this study, the researcher presented a thick description of the research findings in Chapter 4. A thick description of the research methodology is detailed in this chapter (Chapter 2) (Babbie \& Mouton, 2001). The research collected sufficiently detailed data in the natural setting, i.e. the Oluno Correctional Facility where the participants were incarcerated. In this study homogenous, purposive sampling (Johnson \& Davis, 2012) was used to collect data from women who had dumped babies and / or committed infanticide. Table 2.2 summarises the strategy for ensuring transferability aspect of trustworthiness.
Table 2: Criteria for and Application of Transferability

\begin{tabular}{|c|c|c|}
\hline Strategy & Criteria & Application \\
\hline \multirow[t]{3}{*}{ Transferability } & Nominate sample & $\begin{array}{l}\text { Criteria for the female par- } \\
\text { ticipants were identified. }\end{array}$ \\
\hline & $\begin{array}{l}\text { Generalisation } \\
\text { from sample to the } \\
\text { target population }\end{array}$ & $\begin{array}{l}\text { - Data had been collected } \\
\text { until saturation was } \\
\text { reached. }\end{array}$ \\
\hline & Dense description & $\begin{array}{l}\text { - The researcher provided an } \\
\text { adequate and clear data- } \\
\text { base that allowed transfer- } \\
\text { ability of judgement by } \\
\text { other subject matter ex- } \\
\text { perts. }\end{array}$ \\
\hline
\end{tabular}

Dependability: Dependability was maintained through an external inquiry audit, a dense description of the research method, stepwise replication, triangulation, peer examination, and a code-recode procedure (Krefting 1991; Babbie \& Mouton, 2001). The researcher sent the notes that emerged from the interviews, the interpretation of those notes, as well as the voice recordings of the interviews to supervisors for them to check whether the researcher 
adhered to acceptable standards in respect of the research process. The concept of dependability refers to the consistency of research findings in a qualitative research study. Indirectly, the measures of credibility were insured by dependability (Babbie \& Mouton, 2009). Table 2.3 summarises the strategy for ensuring the dependability aspect of trustworthiness.

Table 2: Criteria for and Application of Dependability

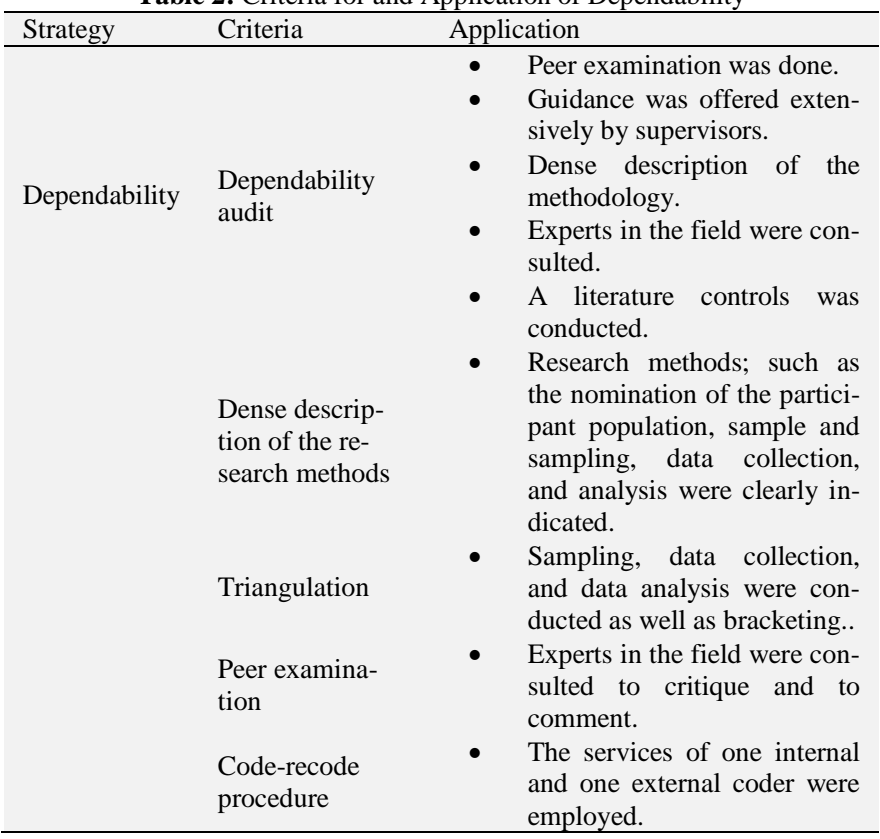

Confirmability: The researcher ensured the safekeeping of the voice recordings, written documents, and notes from the interviews to enable the supervisor to determine whether it was possible to trace the conclusion and interpretation back to their sources and whether the conclusion and interpretation were supported by the inquiries. In this study, confirmability was assured by using triangulation of data collection techniques; such as written field notes and the use of a voice recorder to support verbal responses during a focus group interview and unstructured individual interviews (De Vos et al., 2006). Table 2.4 summarises the strategy for ensuring the confirmability aspect of trustworthiness.

Table 3: Criteria for and Application of Confirmability

\begin{tabular}{|c|c|c|}
\hline Strategy & Criteria & Application \\
\hline \multirow{3}{*}{ Confirmability } & Triangulation & - The researcher conducted un- \\
\hline & $\begin{array}{l}\text { Referential } \\
\text { adequacy }\end{array}$ & $\begin{array}{l}\text { The researcher wrote field } \\
\text { notes and made use of a voice } \\
\text { recorder }\end{array}$ \\
\hline & $\begin{array}{l}\text { independent } \\
\text { decoder }\end{array}$ & $\begin{array}{l}\text { - The researcher made use of a } \\
\text { independent decoder who had } \\
\text { experience in qualitative data } \\
\text { analysis. }\end{array}$ \\
\hline
\end{tabular}

- Situational analysis
Authenticity: Authenticity is the extent to which qualitative researchers fairly and faithfully show a range of different realities in the analysis and interpretation of their data (James, 2008). In establishing authenticity, researchers seek reassurance that both the conduct and evaluation of research are genuine and credible, not only in terms of participants' lived experiences but also with respect to the wider political and social implications of research (Guba \& Lincoln, 1994). Authenticity emphasises the practical outcomes of the research, i.e. providing women who had dumped babies and / or committed infanticide with information to be prepare them for the reintegration process (Bryman, 2012). This approach ensured the tactical authenticity of this research project (Tobin \& Begley, 2004). Table 2.5 summarises the strategy for ensuring the authenticity aspect of trustworthiness.

Table 4: Criteria for and Application of Authenticity

\begin{tabular}{|c|c|c|}
\hline Strategy & Criteria & Application \\
\hline \multirow[t]{5}{*}{ Authenticity } & Fair & $\begin{array}{l}\text { - The researcher presented all value } \\
\text { differences, views, and conflicts of } \\
\text { participants. }\end{array}$ \\
\hline & Ontological & $\begin{array}{l}\text { - The research outcomes increased } \\
\text { understanding. }\end{array}$ \\
\hline & Educative & $\begin{array}{l}\text { - Perspectives of other social group } \\
\text { were better appreciated. }\end{array}$ \\
\hline & Catalytic & $\begin{array}{l}\text { - The research has influenced the par- } \\
\text { ticipants to change. }\end{array}$ \\
\hline & Tactical & $\begin{array}{l}\text { - The research participants have been } \\
\text { empowered by the research to } \\
\text { change. }\end{array}$ \\
\hline
\end{tabular}

\section{Results}

The following result was identified for each and the details of the findings of this phase are discussed in different articles of this study. The aim of the presentation of the finding is for the view of the article to see the flow and the connectivity of findings of the situation analysis, application of the conceptual framework, development of the educational programme and implementation as well as the implementation. partners, family, and the community.

Theme 1: Participants experienced psychological factors that contribute to baby dumping and committing infanticide.

- Sub-theme: Participants experienced feelings of fear, anger, and evil thoughts that contribute to baby dumping and infanticide.

- Sub-theme: Participants experienced feelings of despair.

- Sub-theme: Participants experienced lack of support by family members, male partner, and the community.

- Sub-theme: Participants experienced alcohol and drugs abuse that contributed to baby dumping and infanticide.

Theme 2: Participant experienced socioeconomic factors that contributed to baby dumping and infanticide.

- 2Sub-theme: Participants experienced multiple sexual partners / promiscuity that contributed to baby dumping and committing infanticide.

- Sub-theme: Participants experienced poverty that contributed to 


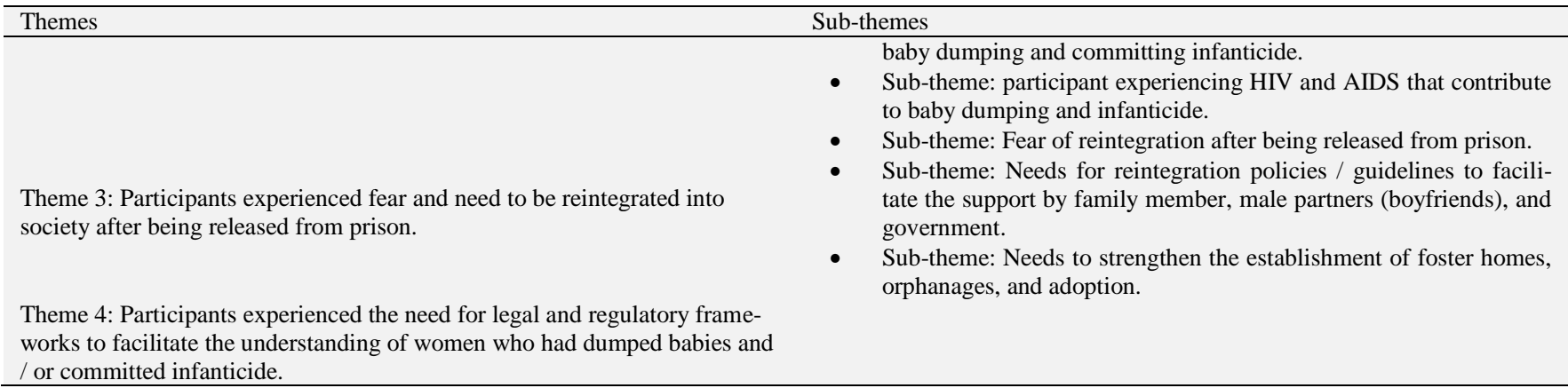

- Conceptual framework

The survey list of Dickoff et all 1968 which includes the context, agent, recipient, dynamics, procedure and terminus serves as basis of the formulation of the conceptual framework development.

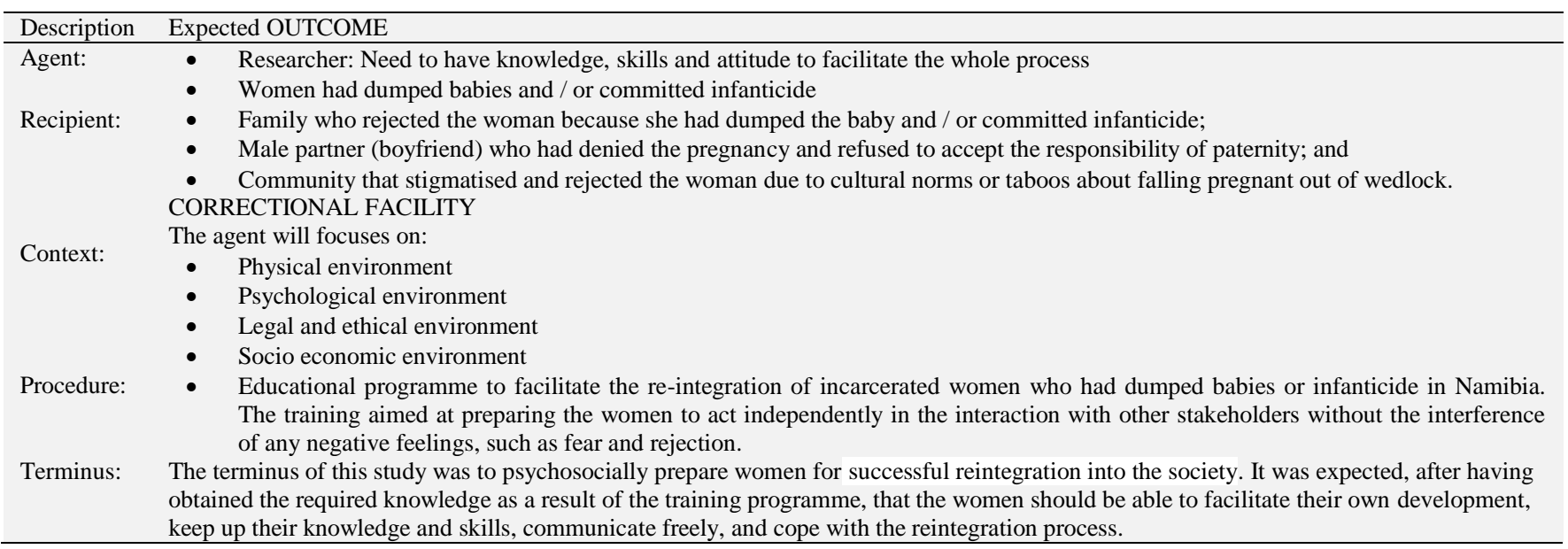

- $\quad$ an educational programme

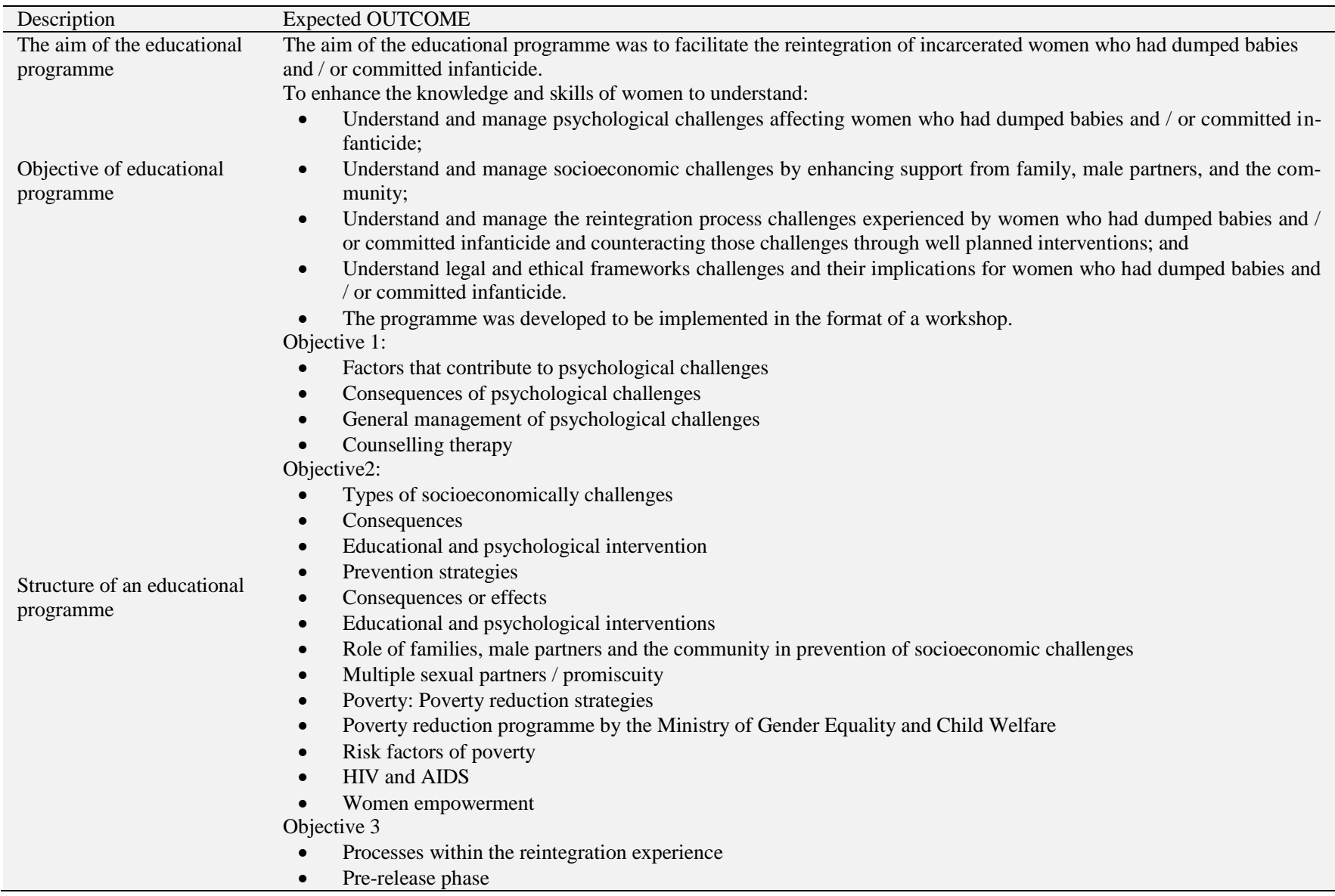




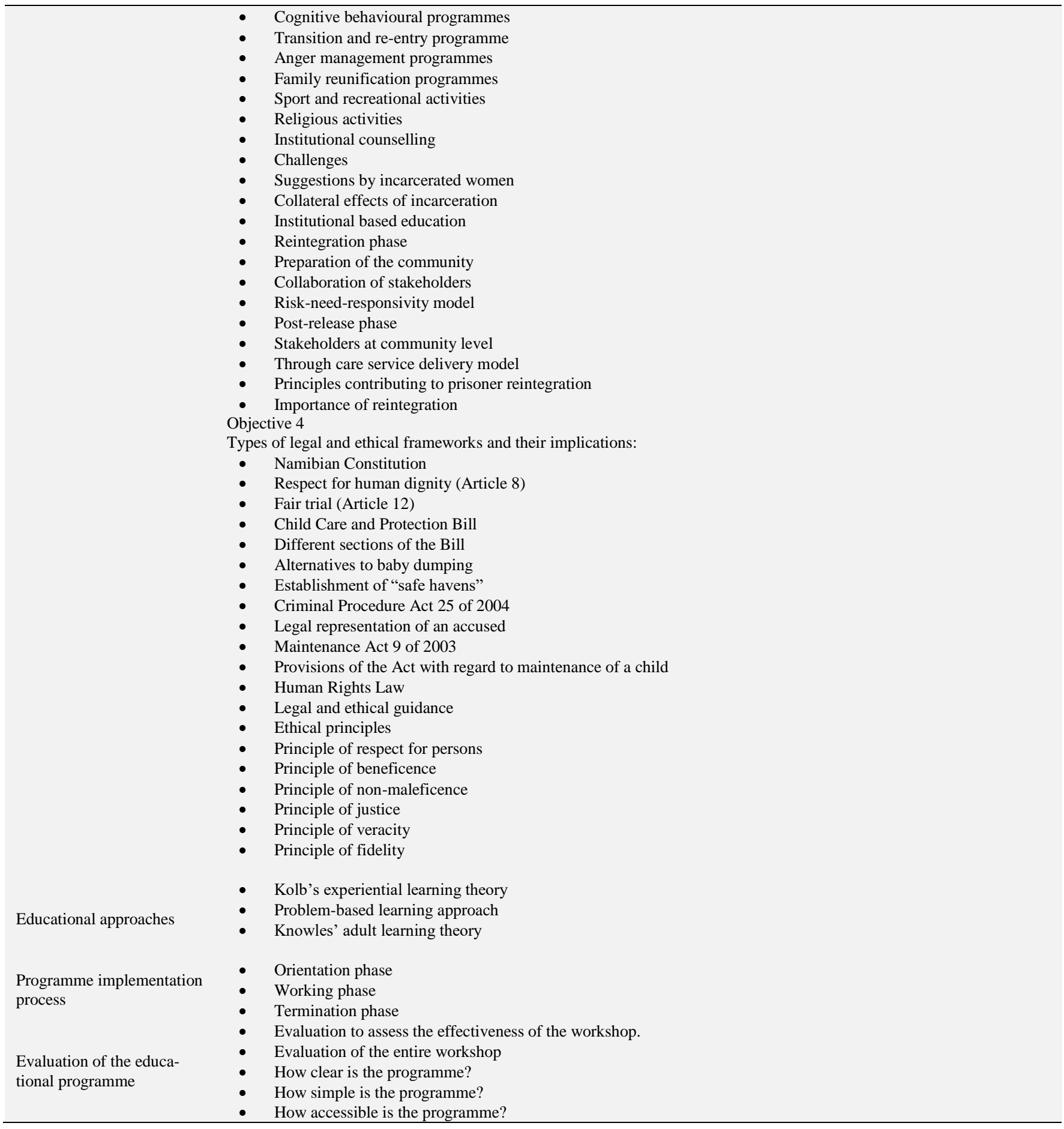

\section{Conclusion and recommendation}

According to LoBiondo-Wood \& Haber (2010), recommendations provide the consumers with a researcher's suggestions about the application of a study in practice, theory, future research, and furnish them with a final perspective on the use or helpfulness of a study. Various recommendations arose from this research study for the Namibian Correctional Services in the Ministry of Safety and Security, as well for further research to be embarked by by the researcher herself at a later stage.

With regard to education and vocational training of women who had dumped babies and / or committed infanticide, the researcher is of the opinion that the NCS should strengthen its existing training and education system in prison in order to properly rehabilitate the women who have dumped babies and / or committed infanticide before they are released. This might be impossible at present due to acute shortage of staff in the NCS that lacks over 60 per cent of the staff complement it needs to run its correctional facilities as a result of the shortage of funds (Uukongo, 2015). The main objective of the NCS is to rehabilitate offenders, and the key is to have competent staff to achieve this objective. Therefore, it is recommended that the Ministry of Safety Security invests more in staff training and development in order to effectively impact the education and the training in the prison system. Another recommendation suggests the upgrading of the knowledge of the correctional officers to keep themselves abreast of all correctional educational programmes. These recommendations might decrease recidivism of women who have dumped babies and / or committed infanticide after they are released to be reintegrated into the society. The researcher is also aware that the Oluno Correctional Facility where this study was conducted currently services Oshana, Omusati, Ohangwena, and Oshikoto and to some extent Kavango West, Kavango East, and the Zambezi Regions. There is a need for proper provision of staff and budget for the Namibian Correc- 
tional Services to run its business effectively otherwise this could hamper the operations of this particular correctional intervention. It is recommended that the focus of future research should be: to explore the experiences of how men need to be encouraged to help address the problem of baby dumping and infanticide; to explore the experiences of fathers who deny taking the responsibility of fatherhood and which punitive measures should be in place to address such problems; and Additional future analyses to examine reintegration success in broader terms by using longitudinal mixed methods approaches.

Gruesome scenes of infants being dumped in rivers, dustbins, and dumpsites have become regular occurrences in Namibia, therefore, there is a need for this kind of training programme for women who have dumped babies and / or committed infanticide. This is a psychosocial educational programme that enables women to know who they are and to understand what despair is that leads to helplessness and hopelessness and how to deal with it. Therefore, it is recommended that all correctional facilities in all the regions under the auspices of the Ministry of Safety and Security should implement this training programme for women who have dumped babies and / or committed infanticide. It is also recommended that the Ministry of Safety and Security should be engaged in partnership with non-governmental organisations, ministries, and all those interested parties who desire to curb the menace of baby dumping and infanticide in Namibia. Baby dumping and infanticide have become a public health problem and it is about time that interventions are implemented to decrease this phenomenon The government of Namibia is facing an enormous problem with baby dumping and infanticide (LAC, 2010) and this should necessitate the government to seek or identify alternative measures to save the babies by augmenting the current policies with adoption and foster home options. It is clear that there are a number of factors that are causing women to take the desperate step of dumping their babies. One contributing factor is that many people are unaware of their options when they fall pregnant and do not want the baby (LAC, 2010). Therefore, other recommendations with regard to the options should include:

- 'Baby boxes' known as baby hatches or angel's cradles where the babies can be safely deposited. These facilities are seen in countries like South Africa (Cape Town), South Korea, Malaysia, China, Indianapolis, and England.

- Babies can be left in safe places like hospitals, police stations, fire stations, and churches under legislation that would help some mothers give up their children safely and anonymously.

- More and clear information about alternatives to baby dumping; such as foster care, adoption, and institutional care. Bill boards should publish information nationwide about alternatives to baby dumping and infanticide; and

Paternity tests to be made more available at a lower cost for the mother and the man who is alleged to be the father of the child While these tests are extremely accurate, they are still far too expensive. Strong punitive actions can then be taken against the culprits who deny paternity.

\section{References}

[1] Ministry of Gender Equality and Child Welfare. Namibia. (2012 2016). National Plan of Action on Gender-Based Violence. Windhoek, Republic of Namibia.

[2] Ministry of Gender Equality and Child Welfare. Namibia. (2009) Baby Dumping. Windhoek: Government Printers.

[3] Ministry of Gender Equality and Child Welfare. (2015). Government of the Republic of Namibia.Namibia. Windhoek: Namibia

[4] Ministry of Health and Social Services. Namibia. (2002). Adolescent Friendly Health Services for Namibia: A training Manual for Health Service Providers. Windhoek: Government Printers. Hubbard, D. (2008). Monograph Series: Baby dumping and Infanticide. Gender Research \& Advocacy Project. Legal Assistance Centre. Windhoek: Namibia.
[5] Lewis, K. (2013). Baby Dumping reported on the rise in Namibia Retrieved November 16, 2014, from www.nshr.org.na/index.php? module $=$ News $\&$ func $=$ display.

[6] Dickoff, J., James, P. and Wiedenbach, E. (1968). Theory in practice discipline Part 1: Practice Oriented Theory. American Journal of Nursing Company. 7(5):415-451. http://dx.doi.org/10.1097/00006199-196809000-00006.

[7] Babbie, E. \& Mouton, J. (2009). The practice of social research $\left(9^{\text {th }}\right.$ ed.). Belmont. Wadsworth.

[8] Babbie, E. R. (2010). The practice of social research $\left(12^{\text {th }}\right.$ ed.). California: Cengage Learning.

[9] Groenewald, T. (2004). A phenomenological research design illustrated. Professional Educational Services, University of South Africa, Florida, South Africa. http://www.ualberta.ca/ iiqm/backissues/31/html/groenewald.html.

[10] Groenewald, T. (2010). Qualitative inquiry growth: Ontology, epistemology \& paradigm. Shift in consumer research to insights from experiences and meanings. Retrieved May 27, 2011, from http://psychsoma.co.za/qualitative-inq uirygrowt/ontologyepistemology paradigm/

[11] Polit, D. F. \& Beck, C. T. (2012). Nursing Research: Generating and Assessing Evidence for Nursing Practice, 9th Edition Philadelphia: Lippincott Williams \& Wilkins

[12] De Vos, A. S. (2009). Research at grassroots: A primer for the caring professions. Pretoria: Van Schaik.

[13] Creswell. J. W. (2008). Educational Research: Planning, Conducting and Evaluating Qualitative \& Quantitative research. Pearson Education: New Jersey.

[14] Roberts, C. M. (2004). The dissertation journey: A practical and comprehensive guide to planning, writing, and defending your dissertation. Thousand Oaks, CA: Corwin Press.

[15] Reichel, M., \& Ramey, M. A. (Eds.). (2009). Conceptual frameworks for bibliographic education: Theory to Practice. Littleton Colorado: Libraries Unlimited Inc.

[16] Babbie, E. \& Mouton, J. (2009). The practice of social research $\left(9^{\text {th }}\right.$ ed.). Belmont. Wadsworth.

[17] Brink, H. L. (2006). Research Methodology for Health Care Professionals. Revised $2^{\text {nd }}$. Cape Town, Juta.

[18] Brink, H. L. (2007). Research Methodology for Health Care Professionals. Revised $2^{\text {nd }}$. Cape Town, Juta.

[19] Burns, N., \& Grove, S. K. (2009). The Practice of Nursing Research: Appraisals, synthesis and generation of evidence (6th edition). St Louis, Missouri: Saunders

[20] Polit, D. F. \& Beck, C. T. (2008). Nursing Research: Generating and Assessing Evidence for Nursing Practice, 9th Edition Philadelphia: Lippincott Williams \& Wilkins.

[21] Hennink, M., Hutter, I and Bailey, A. (2011). Qualitative Research Methods. London. Sage. 